\title{
Shear and turbulence production across subtidal channels
}

\author{
by David K. Ralston ${ }^{1,2}$ and Mark T. Stacey ${ }^{1}$
}

\begin{abstract}
In intertidal regions with subtidal channels, effects of bathymetry on overlying flow vary greatly with tidal stage. Around low water when mudflats and marsh are exposed, flow is constrained to channels, but when water depths are greater, tidal forcing may not necessarily be aligned with meandering channel axes. Flow across the channel can generate strong shear and turbulence at the elevation of the channel banks and can significantly increase turbulent energy in the middle of the water column. Field observations in a mudflat channel of San Francisco Bay indicate that cross-channel shear regularly occurs there early in ebb tides. With increased freshwater flow, baroclinic forcing can enhance shear by decoupling flow between dense water flooding in the channel and fresher water ebbing above the channel banks. A water column numerical model with $k$ - $\varepsilon$ turbulence closure is modified to represent the cross-channel shear production. Numerical results with uniform density indicate that turbulence production increases with the angle between the barotropic tidal forcing and the channel axis. When a longitudinal salinity gradient is imposed, cross-channel shear production contributes to breakdown of periodic stratification. Turbulence produced at the channel banks locally exceeds dissipation, and the excess energy is either lost to buoyancy or diffuses vertically to lower energy regions near the surface and near the bed. The balance among shear production, buoyancy production, and diffusion of turbulence depends on the flow angle and the strength of the longitudinal salinity gradient.
\end{abstract}

\section{Introduction}

Interactions between water column hydrodynamics and the underlying bathymetry are fundamental to flows in coastal and estuarine systems. Rather than idealized approaches with tidally averaged, uniaxial flow through rectangular cross-sections, recent work has recognized that processes that vary tidally or spatially are critical to the flow physics (Uncles, 2002). In estuaries, depth variation between channels and shoals significantly impacts the structure of residual circulation and the response to wind forcing (Li et al., 1998; Wong and Moses-Hall, 1998). Frictional and baroclinic effects associated with the bathymetry generate along-estuary shear and convergent lateral circulation at transitions between channels and shoals (Valle-Levinson et al., 2000). Localized mixing associated

1. Department of Civil and Environmental Engineering, University of California, 631 Davis Hall \#1710, Berkeley, California, 94720-1710, U.S.A.

2. Present address: Woods Hole Oceanographic Institution, Woods Hole, Massachusetts, 02543, U.S.A. email: dralston@whoi.edu 
with bathymetric irregularities can greatly exceed background levels for a flat bottom. At small scales, a shallow, narrow trench across an estuary can produce internal lee waves and elevated mixing downstream (Peters, 1999); at much larger scales in the coastal ocean, submarine canyons and ridges locally enhance turbulence, upwelling, and internal wave generation (Boyer and Davies, 2000). Here we consider a small-scale example of spatial and temporally local mixing due to interactions between flow and bathymetry - in subtidal channels through intertidal mudflats. We initiate the study with field observations of skewed shear and turbulence generation over mudflat channels and then use numerical modeling to evaluate the basic physical processes in shallow stratified and unstratified water columns.

Shallow subtidal channels are regular features of intertidal mudflats, and although channels make up a small fraction of the total intertidal surface area, they are important conduits for flow and scalar transport across mudflats and into salt marshes (Wells et al., 1990; Lawrence et al., 2004). Around low water when mudflats are exposed, flow is confined to channels that continue to drain the region upstream. Around high water when the broad flats are inundated, flow is deep relative to channel depth, and frictional differences between channel and shoal are minimized. Then flow is relatively independent of the bathymetry and responds primarily to the tidal barotropic pressure gradient. As water depth decreases through the ebb, frictional effects become greater on the shoals and the channel captures more of the flow. Frictional effects between channel and shoal are also found in salt marshes, where channels are typically narrower and deeper than on unvegetated mudflats (Friedrichs and Perry, 2001).

Natural tidal channels meander sinuously through marsh and mudflats (Bridges and Leeder, 1976; Gabet, 1998; Fagherazzi et al., 2004), so channel axes are not necessarily aligned with the direction of tidal forcing. At lower tidal stages, flow is constrained to the channel and directed along the channel axis. Around high water when flow is not only in the channel, the tidal barotropic pressure gradient may or may not be oriented along the channel thalweg. Around high water, for example, cross-channel currents can be comparable to along-channel flow (Wells and Park, 1992). Most geomorphic models of tidal channels consider only uniaxial bed stress for erosion and deposition (e.g., Friedrichs, 1995; Fagherazzi and Furbish, 2001; Lawrence et al., 2004). Channel curvature redistributes along-channel momentum across the channel, but flow between channel and shoals is generally neglected (Fagherazzi et al., 2004). When the water elevation is above the channel banks, shear between the upper water column and the region below the channel banks can be a source of turbulence production. This turbulence can affect flow and scalar transport at the channel banks, including sediment erosion and deposition that could alter channel form.

The bathymetric transition can be particularly important when water properties differ between the channel and overlying flow. Despite the small spatial scales of mudflat channels, scalar gradients exist both vertically and laterally. During the winter wet season, freshwater input to the marsh and mudflat can make flow in the intertidal zone strongly 
stratified (Ralston and Stacey, 2005b). Baroclinic forcing directs dense, salty water to the channel and fresher water onto the shoals (Wong, 1994). Because of gravitational effects, the near-bed region of the channel can be much saltier than above the banks, establishing salinity gradients vertically between the bed and the surface, and laterally between channel and shoals. Flow constrained by the channel banks may also have different sediment concentrations than the overlying flow. Lutoclines (sharp gradients in sediment concentration) form when the near-bed region of channels develop much higher sediment concentrations than adjacent mudflat shoals (Wolanski et al., 1988; Adams et al., 1990). As with salinity, sediment stratification changes the mixing regime by suppressing turbulent motions. Because the intertidal zone is a relatively low energy environment, turbulence and mixing due to shear across channel banks could significantly impact net sediment transport.

Analogous cases of topographically-driven shear exist in atmospheric fluid dynamics. In regions with complex terrain, katabatic winds draining down slopes enter air basins at different flow angles depending on hillside orientation. The elevation at which each flow enters the basin depends on its neutral buoyancy level, resulting in skewed, stratified shear between layers of different sources (Fernando et al., 2001). Observations of two or more stacked layers converging from different slope orientations found very strong shear, but little mixing between layers because of stratification (Monti et al., 2002). In alpine valleys, decoupling between the tree canopy and trunk space can create skewed velocity shear such that a significant component of the total Reynolds stress is off the primary flow axis (van Gorsel et al., 2003). Skewed atmospheric shear also occurs where dense valley air is decoupled from winds at higher elevations across the valley axis, and entrainment from the valley into the overlying flow depends on the shear and stratification (Baines, 1995). Most of the laboratory and numerical work in this area has been with laminar flows, and turbulence and mixing in more energetic geophysical applications have received little consideration.

\section{Observations}

Observations were made during field experiments on intertidal mudflats at the edge of Central San Francisco Bay. The study site is a region of mudflat and salt marsh at the University of California's Richmond Field Station, near the city of Richmond, CA (Fig. 1). Two subtidal channels flow through the marsh and onto the mudflat where they converge and flow south toward San Francisco Bay. The geometry of this system has been greatly impacted by development. Marsh on the eastern and western sides of the mudflat has filled in behind two breakwaters, and the mudflat is bounded on the north by a railroad track berm. We focus on the channel that enters the mudflat from the west, Meeker Slough. The channel axis is roughly east/west as it exits the marsh. As the channel crosses the mudflats it curves gently north, continues predominantly eastward for about $200 \mathrm{~m}$, and then curves south toward San Francisco Bay. Cross-sectional bathymetry of the channel near the marsh can be seen in Figure 2. 

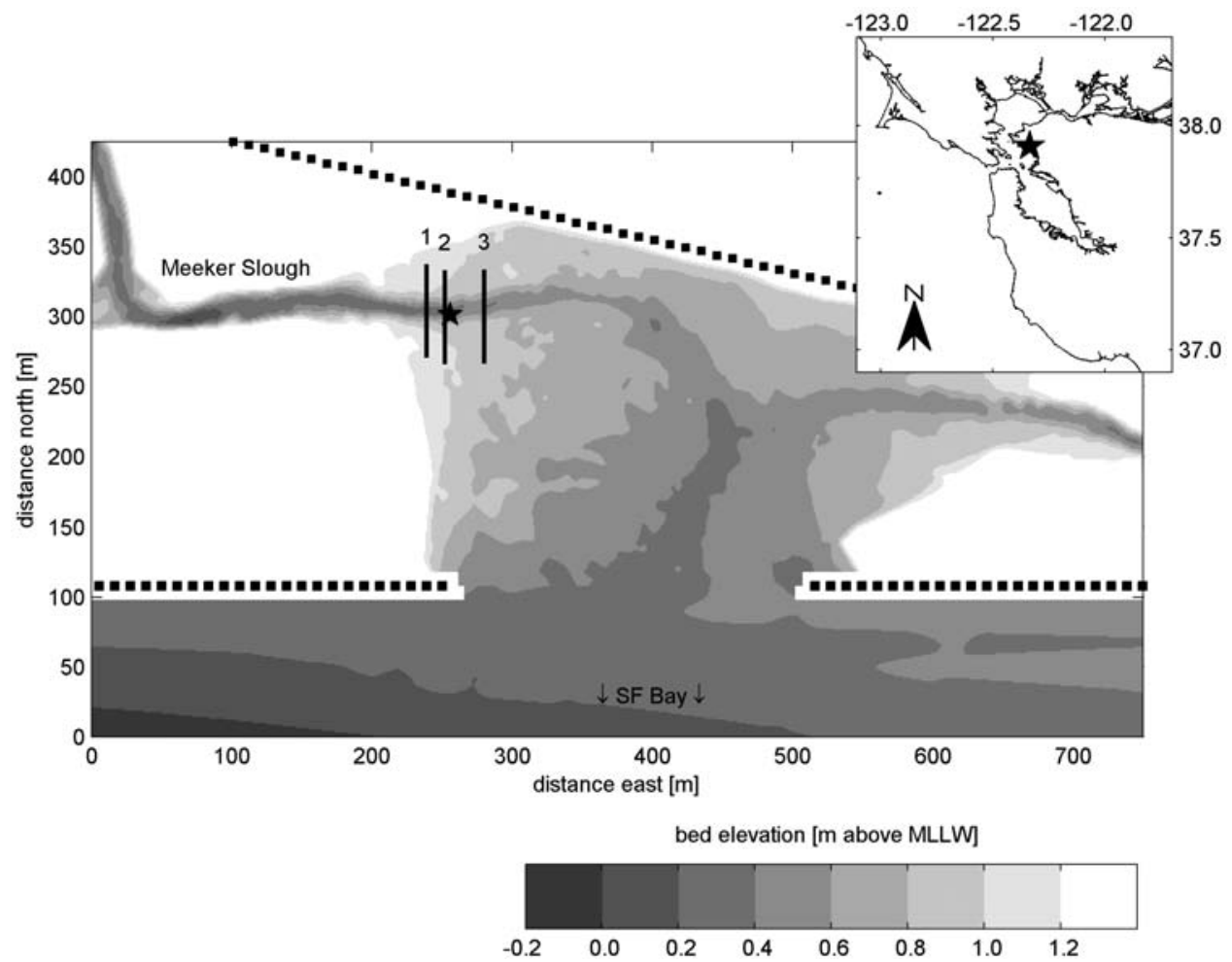

Figure 1. Bathymetry of mudflats and salt marsh at the edge of Central San Francisco Bay near Richmond, CA (bed elevation above mean lower low water [MLLW]). Locations of the ADCP transects $(1,2$, and 3$)$ across the subtidal channel and the moored instrument frame $(\star)$ are marked.

\section{a. Experiment description}

To characterize flow on the mudflats we carried out a series of experiments that combined stationary instrument frames with boat-mounted flow mapping. We consider results from two experiments that examined channel/shoal interaction in Meeker Slough: February 25 to March 2, 2003 and December 19, 2003 to January 3, 2004. Both experiments deployed saw-horse frames in the channel (Fig. 1) with near-bed acoustic Doppler velocimeters (ADVs), and conductivity-temperature-depth sensors (CTDs) at several elevations. The February experiment yielded two days of high frequency data, while the December experiment ran for 10 days but with lower data density. During the February 2003 experiment, boat-mounted flow mapping across the mudflats and channels with an acoustic Doppler current profiler (ADCP) complemented data from the stationary instrument frame.

During the February 2003 experiment, transecting with a 1200-kHz ADCP in shallow water mode (Mode 5) collected single-ping velocity data in $5 \mathrm{~cm}$ bins with the first good 

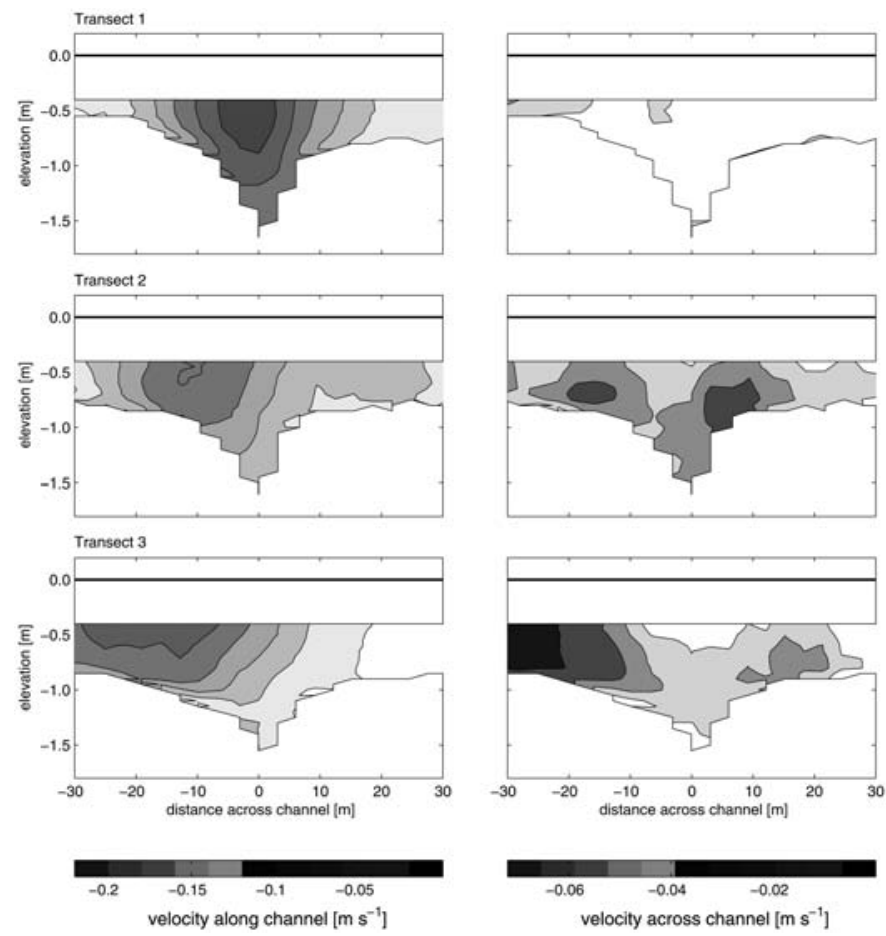

Figure 2. ADCP transects of along-channel velocity (left panels) and across-channel velocity (right panels) during an ebb. Transects are normal to channel axis and centered on the channel thalweg at sequential cross-sections downstream from the marsh; locations are marked in Figure 1. Crosschannel velocities increase moving downstream as flow shifts toward the bay.

bin $30 \mathrm{~cm}$ below the surface. Post-processing of the ADCP data removed records with low correlation and spatially averaged the remaining profiles based on bottom-tracking. Velocity profiles were averaged over $3 \mathrm{~m}$ segments along the transect path. Flow mapping was limited to part of the tidal cycle when there was sufficient water depth on the mudflats to resolve the ADCP signal, roughly $0.5 \mathrm{~m}$ and greater.

Both experiments deployed instrument frames in Meeker Slough near its exit from the marsh, but because the December 2003 experiment had a longer duration, we focus on that moored data set. During that experiment three ADVs were mounted on a sawhorse frame with sample volumes located $0.10 \mathrm{~m}, 0.25 \mathrm{~m}$, and $0.40 \mathrm{~m}$ above the bed. The ADVs sampled at $16 \mathrm{~Hz}$ in 5 minute bursts that repeated either every 15 minutes $(0.25 \mathrm{~m})$ or 30 minutes $(0.10$ and $0.40 \mathrm{~m})$. On the same frame CTDs sampled salinity and temperature $0.10 \mathrm{~m}, 0.35 \mathrm{~m}$, and $0.70 \mathrm{~m}$ above the bed. The CTDs at $0.10 \mathrm{~m}$ and $0.35 \mathrm{~m}$ sampled every 30 seconds and the upper CTD recorded less frequently, every $15 \mathrm{~min}$. The instruments were deployed for two weeks, but 10 days into the experiment a large storm upset the instrument frames and ended data collection. 


\section{b. Flow mapping}

An example of shear across the subtidal channel is apparent in transects across Meeker Slough midway through an ebb tide on February 28, 2003 (Fig. 2). Transect locations are noted on the site map (Fig. 1), and the three transects were within a few minutes of each other. Channel orientation in this region is generally east-west, but the channel does curve slightly north with distance downstream. Velocities have been rotated into along-channel and across-channel components for each ADCP transect, with negative along-channel velocities during the ebb period shown. In transect 1 farthest upstream, flow is centered in the channel and dominantly along the channel axis (Fig. 2a), with little cross-channel velocity (Fig. 2b). About $20 \mathrm{~m}$ downstream at transect 2, the highest velocities are offset from the center of the channel, as flow cuts directly toward the bay rather than continuing along the channel (Fig. 2c). Cross-channel velocities reflect the flow deflection, with velocities that are highest at the channel banks (Fig. 2d). Another $30 \mathrm{~m}$ downstream at transect 3 , the flow is even more offset from the channel axis, in part because of the tidal forcing toward the bay and in part because the channel thalweg is farther north (Fig. 2e). Cross-channel velocities at this downstream cross-section are again significant, with highest velocities at the channel banks (Fig. 2f).

\section{c. Moored instruments: velocity}

Observations of channel flow over multiple tidal cycles with the moored instruments agreed with the flow mapping of skewed shear. Early in ebb tides, the bulk of the flow exiting the marsh heads directly from the channel outlet toward the bay, creating across-channel shear. As the tide drops, the frictional difference between channel and shoal become more pronounced and the velocity vector rotates toward the channel axis. By low water the flow is entirely contained in the channel. This rotation in primary flow axis with tidal stage appears in ADV measurements during December 2003; to collapse multiple tidal cycles of data, we plot velocity vectors against water depth (Fig. 3). The instruments are at fixed elevations, and water depth in the channel describes progression through the tide (Fig. 3a). Velocity vectors have been rotated onto the channel axis by minimizing cross-channel velocity around low water when flow was confined to the channel. This rotation agreed with the physical orientation of the channel at instrument frame, about $20^{\circ}$ north of due east. In the rotated coordinate system, along-channel velocity $(u)$ is positive during floods $\left(270^{\circ}\right)$ and negative during ebbs $\left(90^{\circ}\right)$, and cross-channel flow is the $v$-component.

During floods, flow is almost entirely along the channel axis $\left(270^{\circ}\right)$ regardless of water elevation (Fig. 3b). During ebbs, flow deflects away from the channel following high water slack and shifts toward the south (Fig. 3c). As the ebb continues and the water surface drops, the flow rotates back toward the channel axis $\left(90^{\circ}\right)$. Velocities at all three elevations consistently show this trend of cross-channel flow early in the ebb. Scatter between tidal periods can be related to variability in wind forcing, as southward velocities are particu- 

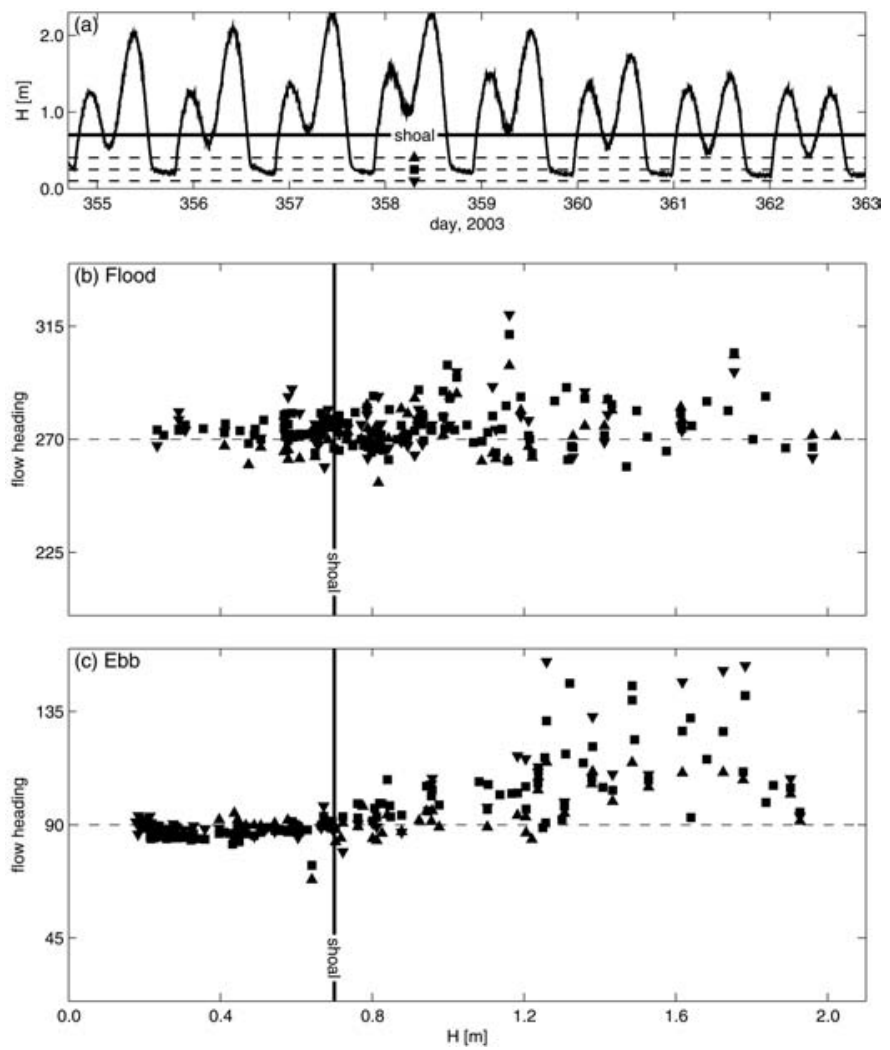

Figure 3. Flow heading against water depth $(\mathrm{H})$ in the channel during December 2003. (a) Water depth in channel, with elevation of ADVs $0.10 \mathrm{~m}(\boldsymbol{\nabla}), 0.25 \mathrm{~m}(\boldsymbol{\square})$, and $0.40 \mathrm{~m}(\mathbf{\Delta})$ above the bed, and elevation of the mudflat shoals (solid gray line). (b) Flow heading during floods (alongchannel $=270^{\circ}$ ); $(\mathrm{c})$ flow heading during ebbs (along-channel $=90^{\circ}$ ). In deeper flow, ebb velocities rotate toward the bay, but as water level falls, flow returns to along-channel.

larly sensitive to wind. Variations between instruments may result from channel curvature and depend on instrument position across the channel.

Considering one of the ebbs in greater detail, we plot ADV velocity vectors at several points during the falling tide on December 22, 2003 (Fig. 4). Shortly after high water, velocity vectors are slightly rotated toward the bay so that the heading is greater than $90^{\circ}$ (Fig. 4(1)). Cross-channel flow intensifies early in the ebb until the magnitudes of alongand across-channel flows are nearly equal and the heading is $140^{\circ}$ to $150^{\circ}$ (Fig. 4(2)). Finally, approaching low water, flow is dominantly along the channel axis at all elevations (Fig. 4(3)). This is a typical sequence at the instrument frame, but upstream or downstream of there the magnitude of the cross-channel shear is likely different. Upstream in the marsh, flow is constrained by vegetation and deeper channel walls so it is channelized for more of 

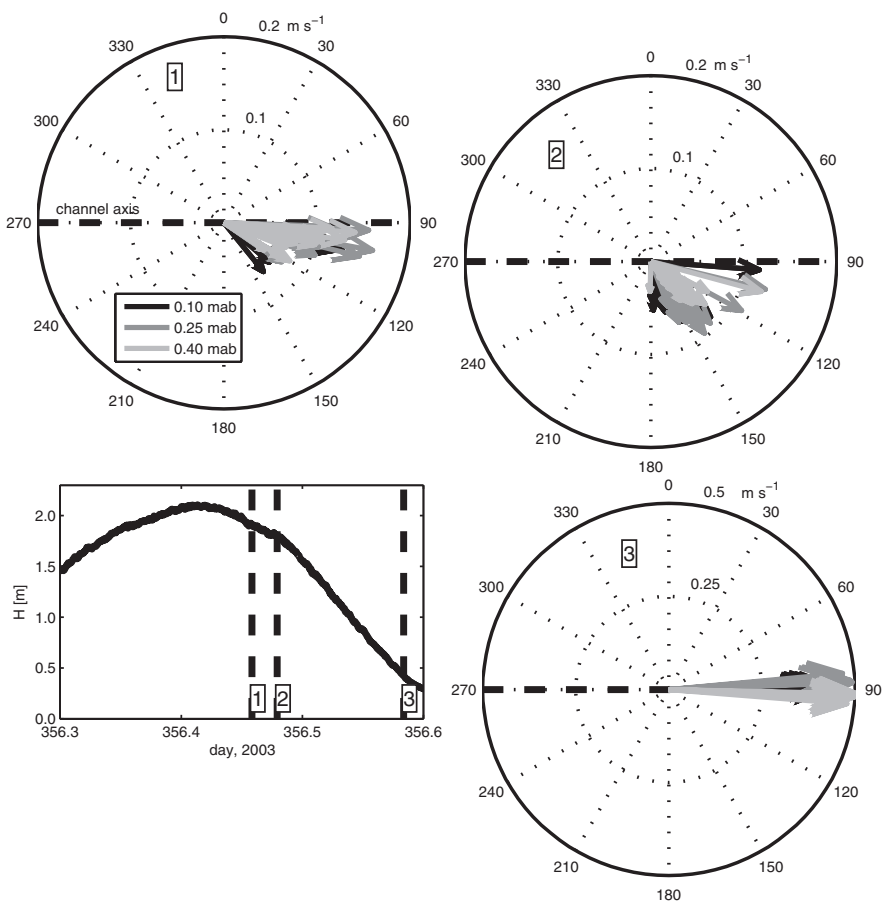

Figure 4. Velocity at ADVs $0.10 \mathrm{~m}, 0.25 \mathrm{~m}$, and $0.40 \mathrm{~m}$ above the bed, at three times during an ebb; water depth $(\mathrm{H})$ in the channel is in the lower left panel. Velocity vectors rotate across the channel early in the ebb (1 and 2), but return to along-channel flow as water surface falls (3).

the tidal cycle. Downstream the shear depends on the orientation of the channel with respect to the shortest path to the bay.

The December 2003 experiment was during the winter wet season, so there was significant freshwater input to the system. As a result there was a strong density gradient between the marsh and the bay that contributed to both periodic stratification and a baroclinic pressure gradient up the channel (Ralston and Stacey, 2005a). Stratification was strongest during ebbs, and this vertical density structure interacted with the skewed velocity shear. During the ebb of December 23, 2003 (one day after the data in Fig. 4), we observe two-layer flow in the channel. Midway through the ebb, a saltier lower layer moves upstream while a fresher layer above it ebbs off the channel axis toward the bay (Fig. 5). The salinity sensors (Fig. 5b) and lower ADVs (Fig. 5c) were separated vertically by only $0.25 \mathrm{~m}$. This ebb coincided with wind from the south at about $5 \mathrm{~m} \mathrm{~s}^{-1}$ that pushed bay water up onto the mudflats. Saltier bay water moved up the channel with the wind, but the surface layer of fresher water continued to ebb out of the marsh. The dense lower layer was constrained to the channel while the upper layer was free to rotate with the barotropic forcing, creating strong shear in both along- and across-channel velocity profiles. 


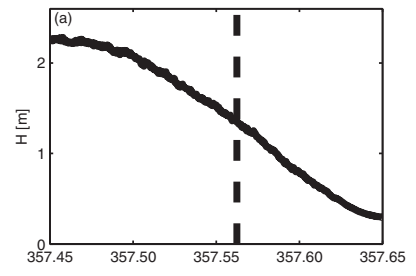

(c)
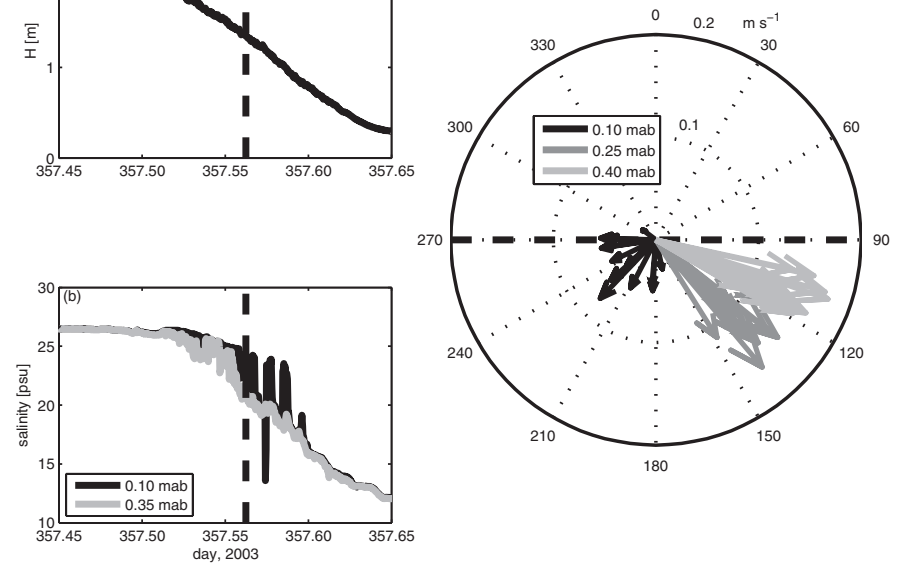

Figure 5. Skewed, stratified flow in the channel. (a) Water depth $(\mathrm{H})$ and (b) salinity $0.10 \mathrm{~m}$ and $0.35 \mathrm{~m}$ above the bed. (c) Velocity vectors $0.10 \mathrm{~m}, 0.25 \mathrm{~m}$, and $0.40 \mathrm{~m}$ above the bed. Because of recent precipitation and local wind forcing, near-bed flow was upstream, but higher in the water column flow ebbed across the channel axis.

\section{d. Moored instruments: turbulence}

Turbulence production in the subtidal channel reflects the changing influence of bathymetry with tidal stage. Shear production is broken into along-channel $(u)$ and across-channel $(v)$ components: $P_{u}=-\overline{u^{\prime} w^{\prime}}(\partial \mathrm{U} / \partial \mathrm{z})$ and $\mathrm{P}_{\mathrm{v}}=-\overline{v^{\prime} w^{\prime}}(\partial \mathrm{V} / \partial \mathrm{z})$, where $\overline{u^{\prime} w^{\prime}}$ and $\overline{v^{\prime} w^{\prime}}$ are Reynolds stresses and $\partial \mathrm{U} / \partial \mathrm{z}$ and $\partial \mathrm{V} / \partial \mathrm{z}$ are velocity shears. Each component is plotted against tidal stage for two elevations above the channel bed and divided into flood and ebb periods (Fig. 6). The time series of water depth in the channel provides reference elevations for the measurements (Fig. 6a). Along-channel shear production $P_{u}$ is greatest around low water at the beginning of floods and end of ebbs (Fig. 6b). Turbulence is generated from shear at the bed when the tidal forcing and along-channel velocities are strongest. In contrast, the across-channel shear production $\left(P_{v}\right)$ has a maximum around mid-tide during ebbs (Fig. 6c). This corresponds with the across-channel shear before flow is constrained to the channel. Across-channel shear production during ebbs is stronger between the upper ADVs than between the instruments closer to the bed, consistent with shear that is greatest at the channel banks. Along-channel shear production is generally stronger between the lower ADVs because shear and turbulence production are generated at the bed. Note that along-channel production dominates the turbulence budget for most of the tidal cycle, but around mid-ebb the across-channel contribution can be the same magnitude or larger in the upper water column.

The field observations indicate that the bathymetric influence of the subtidal channel varies greatly with tidal stage. The local geometry is such that at the beginning of ebbs, 

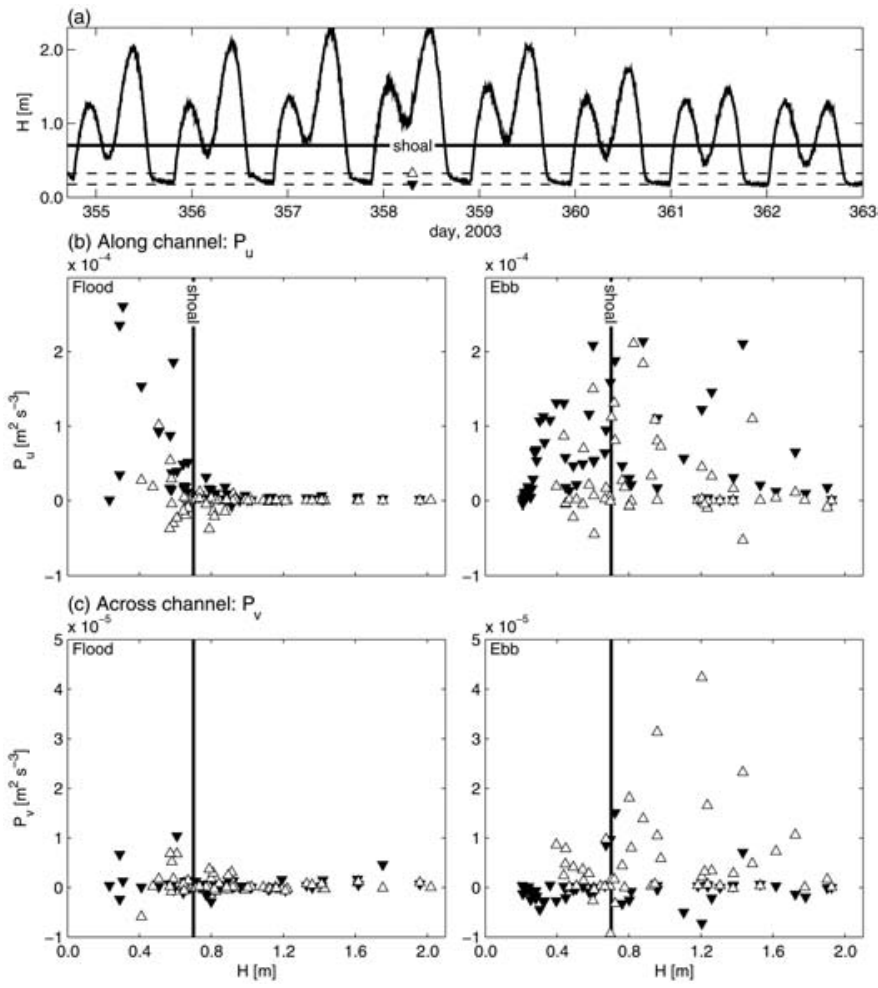

Figure 6. Shear production in the channel. (a) Water depth, elevations of measurements centered $0.18 \mathrm{~m}(\triangle)$ and $0.33 \mathrm{~m}$ above the bed $(\boldsymbol{\nabla})$, and elevation of the mudflat shoals (solid gray line). (b) Along-channel shear production $\left(P_{u}\right)$ against water depth for floods and ebbs, and (c) acrosschannel shear production $\left(P_{v}\right)$; note different scales. $P_{u}$ is greatest near the bed during both floods and ebbs, but $P_{v}$ is greatest mid-tide between the upper ADVs.

flow in the upper water column is partially across the channel axis (Fig. 7a). The offset between the channel axis and the barotropic forcing generates cross-channel shear that in turn produces turbulence mid-water column. During the falling tide, the cross-channel component of turbulent shear production can become a substantial part of the total turbulence budget. Below the channel banks flow is more constrained to the channel axis, particularly in a stratified water column where dense near-bed flow is decoupled from the upper water column. As water level drops through the ebb, more flow is captured by the channel and the dominant velocity direction is along the channel axis (Fig. 7b).

The skewed shear results from the orientation of the mudflat channel relative to the local tidal forcing, and the geometry of the intertidal zone at the study site has been substantially influenced by anthropogenic modifications. However, most natural tidal channels are also sinuous, and channel location can be constrained by geologic outcroppings or levees similar to the breakwaters at the field site. Generally, the effect can be summarized as the 

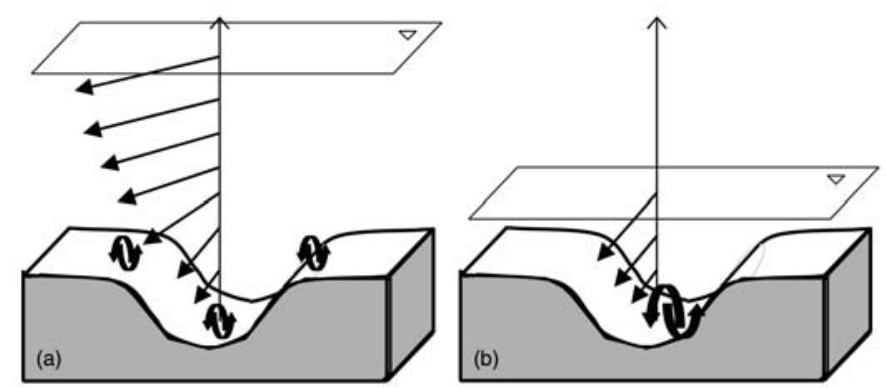

Figure 7. Schematic summary of shear across subtidal channel. (a) Around high water, flow in the upper water column is across the channel while near-bed flow remains constrained to the channel; (b) approaching low water flow is unidirectional along the channel axis.

variable role of bathymetry with water depth for hydrodynamics in shallow, threedimensional tidal flows.

To focus on the fundamental hydrodynamic processes behind the observations, we turn to a numerical model that calculates velocity and turbulence parameters in a onedimensional water column. Rather than a simulation of conditions at the field site, our numerical modeling approach defines idealized cases based on key features of the observations. The basic water column model cannot possibly capture the spatial and temporal complexity of bathymetry and forcing in the observations, but it is a useful tool to study underlying hydrodynamic processes important at this location and elsewhere.

\section{Numerical model}

We apply the numerical model to evaluate how bulk flow and turbulence in the mudflat channel vary with orientation of the barotropic pressure gradient relative to the channel axis. We use the General Ocean Turbulence Model (GOTM), a one-dimensional water column that solves for momentum, salt, and heat transport (Burchard et al., 1999). In the $\mathrm{x}$-direction, $u$-momentum budget is

$$
\frac{\partial u}{\partial t}=\frac{\partial}{\partial z}\left(v_{t} \frac{\partial u}{\partial z}\right)-g \frac{\partial \zeta}{\partial x}-\frac{g}{\rho_{0}} \int_{z}^{\zeta} \frac{\partial\left(\rho-\rho_{0}\right)}{\partial x} d z-C_{f} u \sqrt{u^{2}+v^{2}}-\frac{1}{\tau_{R}(u)}\left(u-u_{o b s}\right)
$$

where the first term on the right-hand side is the vertical flux of momentum due to the turbulent eddy viscosity $\left(v_{t}\right)$, the second term is the external pressure gradient, the third term is the internal pressure gradient, the fourth term is bottom friction, and the fifth term nudges of the velocity profile toward observations using a relaxation time scale $\left(\tau_{R}\right)$. Rather than an explicitly defined surface slope of $\partial \zeta / \partial x$, the barotropic forcing is calculated by matching model output to a given velocity time series (Burchard, 1999). GOTM then applies the required barotropic pressure gradient to generate the defined depth-averaged velocity. The equation for the $v$-momentum balance along the y-axis is analogous. 
In the following calculations, the internal pressure gradient depends only on the longitudinal salinity gradient, $\partial \mathrm{S} / \partial \mathrm{x}$. The salinity profile is calculated based on vertical turbulent mixing and advection of $\partial \mathrm{S} / \partial \mathrm{x}$ according to

$$
\frac{\partial S}{\partial t}+u \frac{\partial S}{\partial x}+v \frac{\partial S}{\partial y}=\frac{\partial}{\partial z}\left(K_{z} \frac{\partial u}{\partial z}\right)
$$

where $K_{z}$ is the turbulent eddy diffusivity. To calculate $v_{t}$ and $K_{z}$, GOTM offers several turbulence closure options, including algebraic, one-equation, and two-equation models. The following calculations implement the two-equation $k$ - $\varepsilon$ closure (Rodi, 1987), using stability constants from Canuto et al. (2001) (Burchard and Bolding, 2001). GOTM has been tested for a wide range of applications, from idealized fluid dynamics problems (e.g., Umlauf and Burchard, 2003) to estuarine and coastal ocean applications (e.g., Simpson et al., 2002).

\section{a. Model description}

The water column for this application is scaled to intertidal zone channels, with a mean water depth of $2.0 \mathrm{~m}$ and sinusoidal water surface variation of $1.0 \mathrm{~m}$ amplitude. The model grid is an evenly spaced sigma-coordinate system with bottom boundary condition of fixed roughness. To set the external pressure gradient, we define a depth-averaged velocity time series that is sinusoidal with 12 hour period and $0.4 \mathrm{~m} \mathrm{~s}^{-1}$ magnitude, again scaled by velocity observations at the field site. To vary the incident angle of the flow, we rotate the orientation of the velocity vector from entirely along the $\mathrm{x}$-axis $\left(\theta=0^{\circ}: u=0.4 \mathrm{~m} \mathrm{~s}^{-1}\right.$ and $\left.v=0 . \mathrm{m} \mathrm{s}^{-1}\right)$ to flow only along the y-axis $\left(\theta=90^{\circ}: u=0 . \mathrm{m} \mathrm{s}^{-1}\right.$ and $\left.v=0.4 \mathrm{~m} \mathrm{~s}^{-1}\right)$. The depth-averaged velocity magnitude remains constant, so net flow through the water column is constant with rotation of the pressure gradient.

To simulate cross-channel shear in the one-dimensional model, we compare cases with and without an idealized subtidal channel. For the channel cases, cross-channel flow is constrained below the channel banks by setting a no-flux condition in the lower water column. The channel is defined as the bottom $1.0 \mathrm{~m}$ of the grid, and the model relaxes to $\mathrm{v}=0$ in cells below the channel banks. This approach utilizes the existing capacity in GOTM to relax calculated velocities to observations, with modifications to the code to relax only the v-velocity and only in cells below the channel banks. We are interested in comparing conditions in subtidal channels with conditions on adjacent mudflats, so the channel cells are added to the total depth of the unchannelized (shoal) case. We compare results from these two cases, a 2-m deep (mean) water column on the mudflat shoals and a $3-\mathrm{m}$ deep water column in the channel where the bottom $1 \mathrm{~m}$ of flow is constrained in the cross-channel direction. Because of the cross-channel constraints and the decision to maintain constant depth-averaged velocity with rotation of flow, the implied pressure gradient increases as flow becomes more normal to the channel axis. 

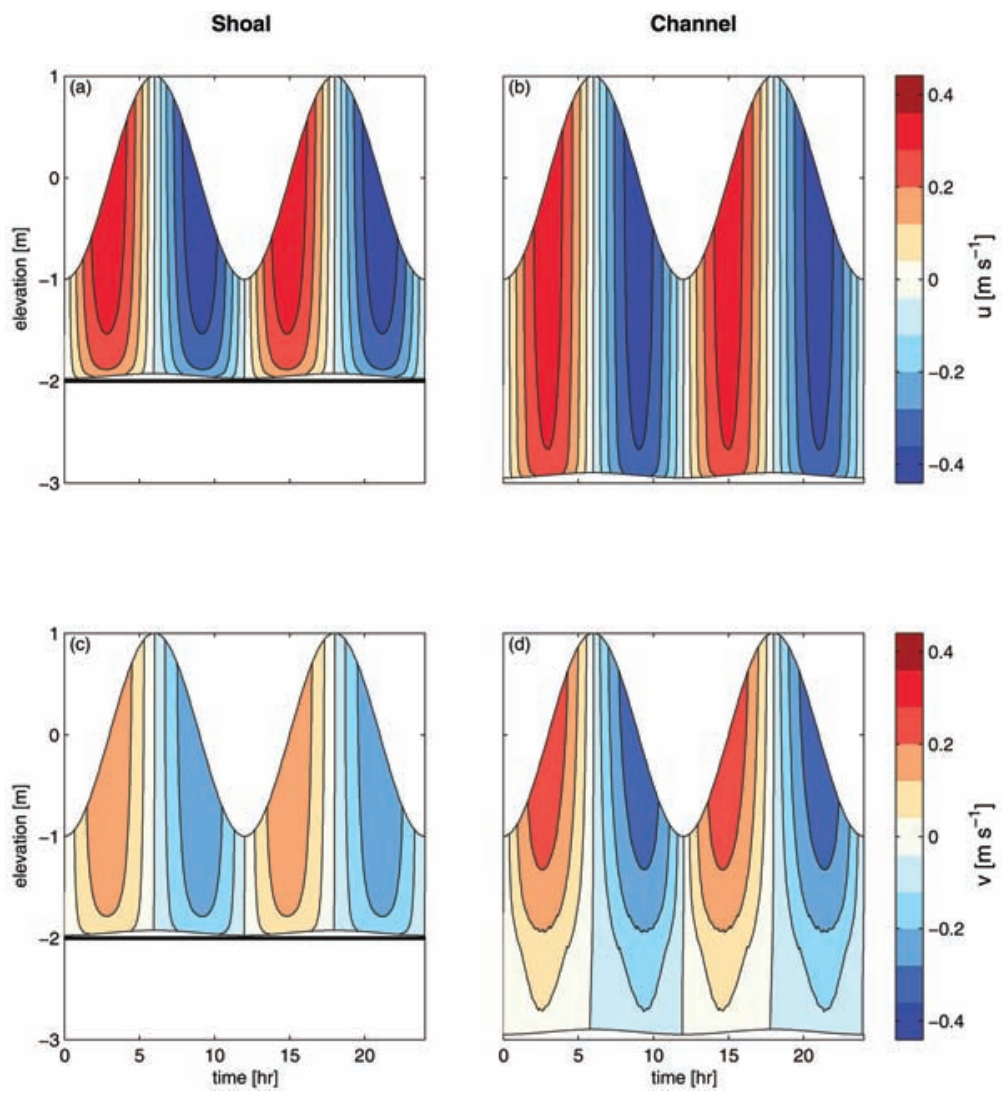

Figure 8. Numerical model results for shoal (left panels) and subtidal channel (right panels) cases. (a-b) Along-channel $(u$, flood $>0$ ) and (c-d) across-channel $(v)$ velocities reflect barotropic pressure forcing oriented $30^{\circ}$ off the channel axis.

\section{b. Uniform density}

The initial discussion focuses on results with constant salinity and temperature, and later we consider effects of salinity stratification. Along-channel $(u)$ and across-channel $(v)$ velocities for the shoal and channel cases are shown for a pressure gradient angle of $30^{\circ}$ over two tidal periods (Fig. 8). The shoal case reflects the external forcing, with maximum along-channel velocities approximately double the maximum across-channel velocities (Fig. 8a/c). The channel case is forced at the same angle, but the velocity profile is very different where the $\mathrm{v}$ component is constrained below the channel banks. Along channel velocities are similar to the shoal case (Fig. 8b), but across-channel velocities are near zero in the bottom $1 \mathrm{~m}$, and increase above the channel banks (Fig. 8d).

The alteration of the velocity profile appears in the velocity shear. For the shoal case, the total shear $(\partial u / \partial z)^{2}+(\partial v / \partial z)^{2}$ is concentrated near the bed, where the no slip condition forces the velocity to zero (Fig. 9a). Shear is also strong near the bed for the channel case, 
Shoal
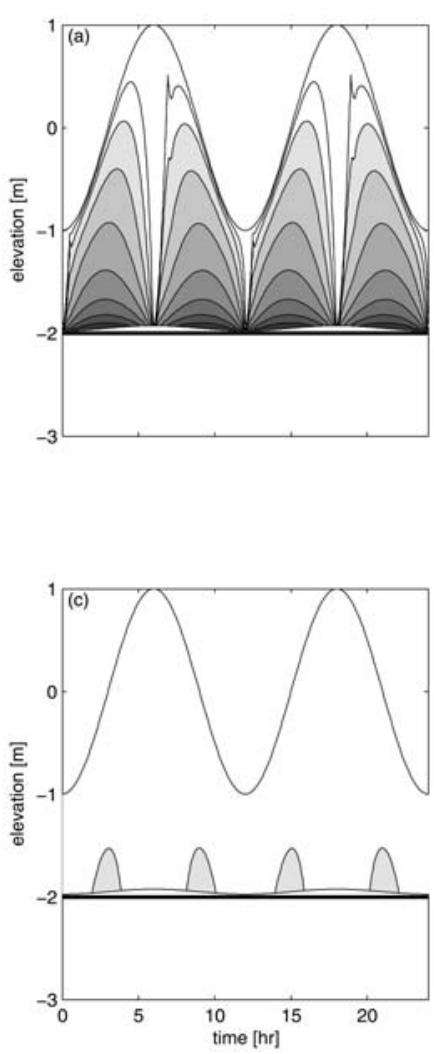

Channel
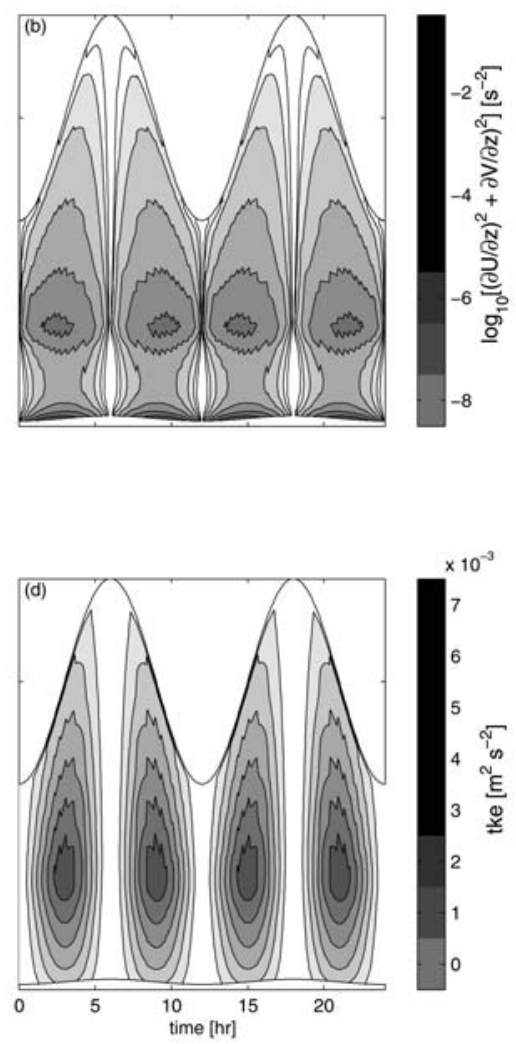

Figure 9. Numerical model results of $(a-b)$ shear $\left((\partial U / \partial z)^{2}+(\partial V / \partial z)^{2}\right)$ and $(c-d)$ turbulent kinetic energy (tke) for shoal and subtidal channel cases with forcing $30^{\circ}$ off the channel axis.

but a second region of high shear is produced near the channel banks at $z=-2 \mathrm{~m}$ (Fig. 9b). For the shoal case, turbulence is produced near the bed and decreases with elevation in the water column (Fig. 9c). For the channel case, there is again production near the bed, but the strongest turbulence is mid-water column near the channel banks (Fig. 9d). Turbulence produced by shear at the channel walls significantly increases the total turbulent energy in the water column. The depth-average turbulent kinetic energy for the channel case is 6 to 8 times greater than the shoal case through much of the tidal cycle.

\section{c. Longitudinal density gradient}

During the wet season, the mudflat channel water column stratified during each ebb tide. Periodic stratification resulted from tidal straining of the longitudinal density gradient between marsh and bay. To incorporate density forcing into the water column model, we impose a longitudinal salinity gradient $(\partial \mathrm{S} / \partial x)$ of $1.5 \mathrm{psu} \mathrm{km}^{-1}$. Although $1.5 \mathrm{psu} \mathrm{km}^{-1}$ is a 


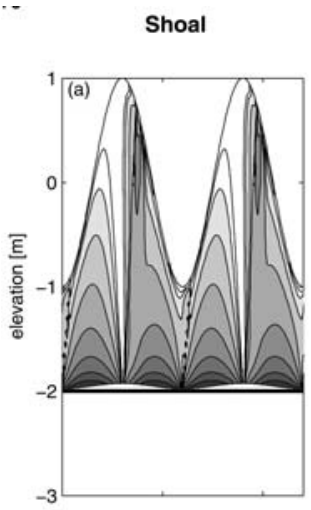

Channel, $\theta=0^{\circ}$
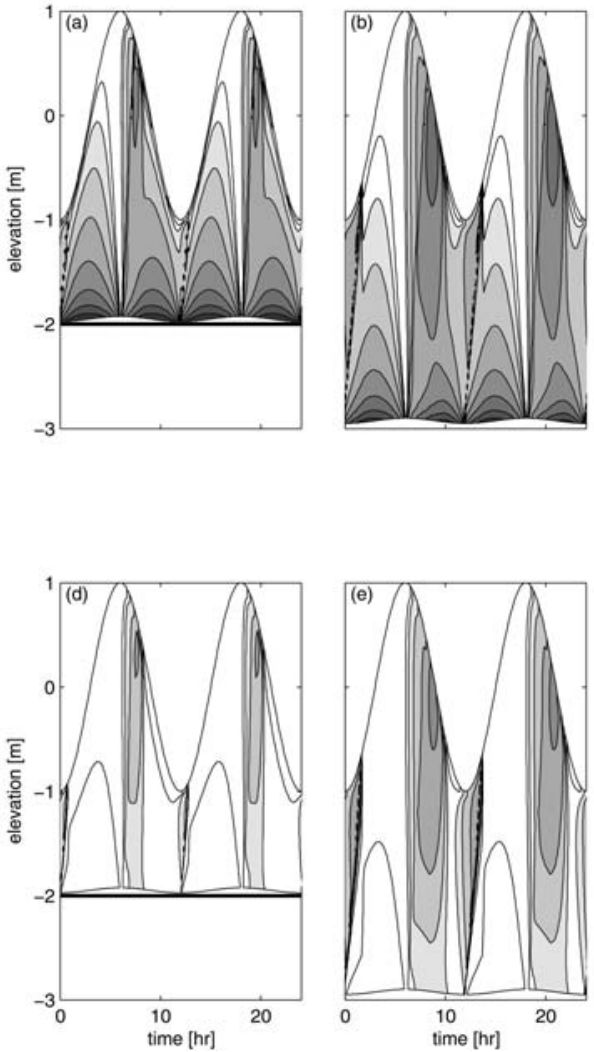

Channel, $\theta=30^{\circ}$
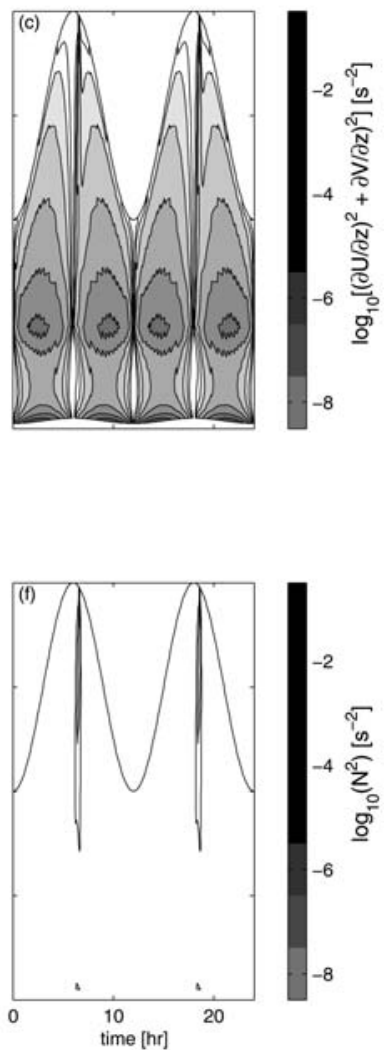

Figure 10. Numerical model results of $(\mathrm{a}-\mathrm{c})$ shear $\left((\partial U / \partial z)^{2}+(\partial V / \partial z)^{2}\right)$ and $(\mathrm{d}-\mathrm{f})$ stratification $\left(N^{2}\right)$ for shoal case and for channel case with barotropic forcing entirely along-channel $\left(0^{\circ}\right)$ and partially across-channel $\left(30^{\circ}\right)$. All cases have $\partial S / \partial x=1.5 \mathrm{psu} / \mathrm{km}$.

relatively strong gradient for many estuarine settings, it is more than an order of magnitude lower than the maximum $\partial S / \partial x$ observed in the field (Ralston and Stacey, 2005a). During the winter, $\partial S / \partial x$ in tributary channels varied tidally from less than $1 \mathrm{psu} \mathrm{km}^{-1}$ to more than $50 \mathrm{psu} \mathrm{km} \mathrm{km}^{-1}$; the tidal average was 10 to $15 \mathrm{psu} \mathrm{km}^{-1}$. In the model, $\partial S / \partial x$ imposes a baroclinic pressure gradient in addition to the barotropic forcing. To quantify effects of cross-channel shear on water column dynamics, the longitudinal salinity gradient is fixed along the channel axis while the baroclinic pressure gradient is rotated with respect to the channel (i.e., $\partial S / \partial x=1.5 \mathrm{psu} \mathrm{km}^{-1}$ and $\partial S / \partial y=0$ psu km${ }^{-1}$ ).

In the shoal case, $\partial S / \partial x$ impacts both the velocity shear and the stratification (Fig. 10a/d); these results can be compared with the uniform density case (Fig. 9a). The combination of barotropic and baroclinic forcing results in strong shear near the bed, but shear is also enhanced near the surface midway through ebbs (Fig. 10a). The sheared water column 
during ebbs corresponds with increased stratification as measured by the buoyancy frequency $N^{2}=g / \rho_{0}(\partial \rho / \partial z)$ (Fig. 10d). Straining of the longitudinal density gradient imposes a stabilizing buoyancy flux that increases stratification during ebbs (Simpson et al., 1990). Stratification suppresses turbulent mixing, reduces the eddy viscosity, and permits greater velocity shear in a positive feedback. However, as the water surface falls the stratified region is brought closer to the bed where stronger turbulence mixes away the stratification. Consequently, after a brief period of stratification in the upper water column, $N^{2}$ decreases and the water column is unstratified for the remainder of the tide. Periodic stratification due to tidal straining has been observed in shallow estuaries with depths similar to the model domain (Chant and Stoner, 2001; Ralston and Stacey, 2005b).

The channel case, with flow solely along the channel axis $\left(\theta=0^{\circ}\right)$, is similar to the shoal case but with a deeper water column. The added meter of depth increases baroclinic circulation such that both shear and stratification during ebbs are stronger than in the shallower shoal system (Fig. 10b/e). Stratification remains strong through the end of the ebbs and decreases during floods until the water column is well-mixed by high water. Midway through ebbs, shear near the surface is much stronger than the maximum near-bed shear in the uniform density case. However, because of strong stratification this shear does not produce significant turbulence.

When the barotropic pressure gradient is rotated to $\theta=30^{\circ}$ off the channel axis, cross-channel shear provides an additional source of turbulent mixing to the water column (Fig. 10c/f). Shear with the longitudinal density gradient (Fig. 10c) is very similar to the shear in the uniform density case (Fig. 9b). Shear production near the channel banks is such a strong source of turbulence that stratification does not develop despite the same $\partial S / \partial x$ (Fig. 10f). Without stratification the water column above the channel banks remains relatively unsheared compared with the along-channel case $\left(\theta=0^{\circ}\right)$. Turbulent shear production at the channel banks adds mixing energy to overcome the stabilizing buoyancy of advection of $\partial S / \partial x$, and the system switches from periodically stratified when $\theta=0^{\circ}$ to almost entirely well mixed when $\theta=30^{\circ}$.

We consider in greater detail turbulence generation as flow is rotated off the channel axis for the case with $\partial \mathrm{S} / \partial \mathrm{x}$ (Fig. 11). As the flow axis rotates from $\theta=0^{\circ}$ to $15^{\circ}$, depth-averaged turbulent kinetic energy in the channel case increases; the shallower shoal case is also plotted for reference (Fig. 11a). In all cases, turbulence is more energetic during floods than during ebbs. As the flow angle becomes more oblique to the channel axis and cross-channel shear intensifies, the peak turbulent energy during ebb occurs earlier in the tide. The rapid increase in turbulent energy during ebbs corresponds with the breakdown of stratification (Fig. 11b). For $\theta=0^{\circ}, N^{2}$ is large early in the ebb but begins to decrease as the water level falls and velocities increase. When the flow angle is offset slightly so that $\theta=5^{\circ}$, shear at the channel banks increases turbulence production and stratification breaks down earlier during both ebb and flood. With additional rotation of the flow axis, turbulence production increases, so that for $\theta=15^{\circ}$ the entire tidal cycle is unstratified except for the first 2 hours of the ebb. Although the change in flow angle is 

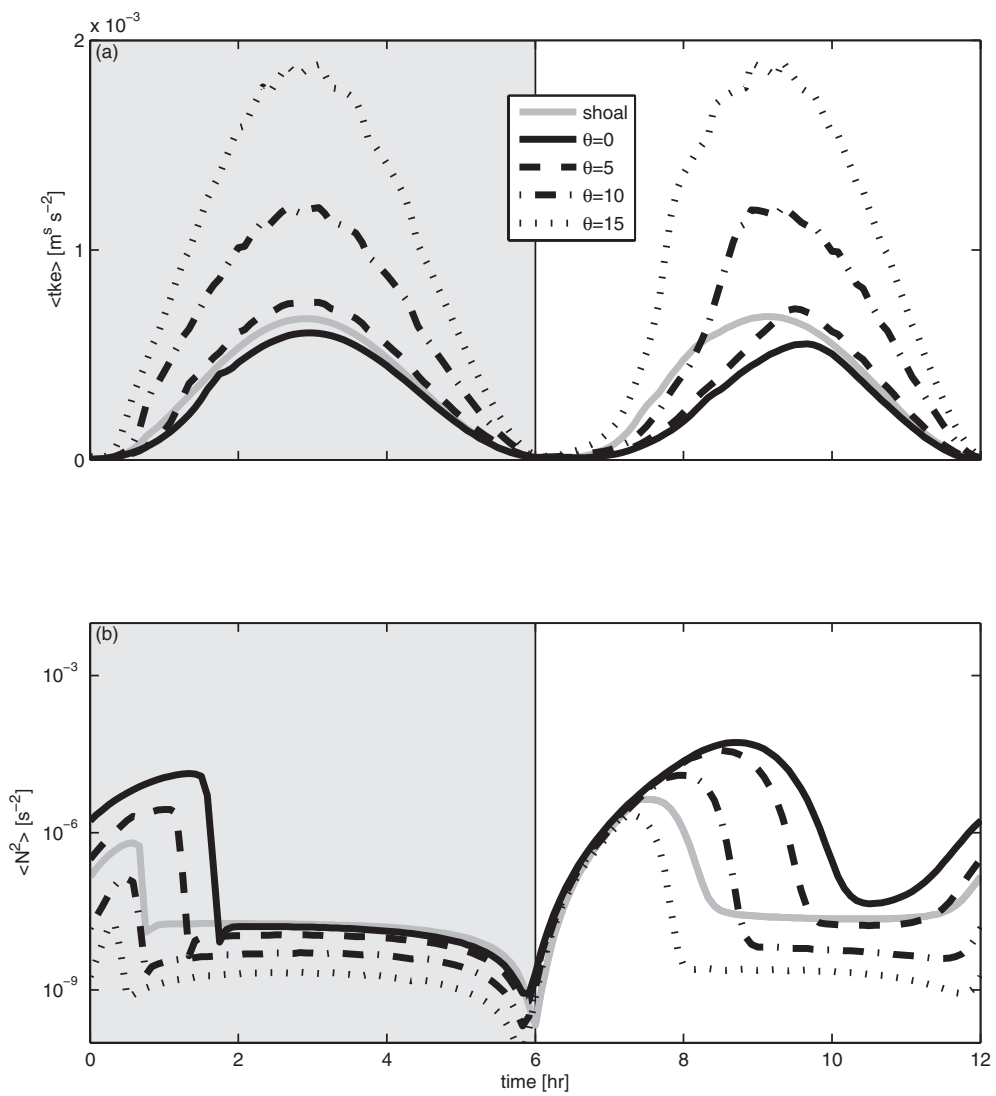

Figure 11. Numerical model results of (a) depth averaged turbulent kinetic energy ( $\langle$ tke $\rangle)$ and (b) stratification $\left(\left\langle N^{2}\right\rangle\right)$ for shoal and channel cases with barotropic forcing oriented $0^{\circ}, 5^{\circ}, 10^{\circ}$, and $15^{\circ}$ across the channel.

slight, the turbulence from shear across the channel banks significantly alters the density structure of the water column.

\section{d. Turbulence budget}

The turbulent energy that is injected into the water column from shear at the channel banks must be consumed to maintain energy conservation. For unstratified flow, shear production $(P)$ is often assumed to locally balance energy dissipation to heat $(\varepsilon)$. When the water column is stratified, the potential energy of buoyancy production $(B)$ is an additional consideration - stable stratification is an energy sink $(B<0)$, and unstable stratification is an energy source $(B>0)$. The remaining terms in the turbulent energy budget are unsteadiness $(\partial k / \partial t)$, and turbulent energy transport that can be treated as a diffusive term $\left(\partial / \partial z(D \partial k / \partial z)\right.$, or simply $D_{k}$ in the following notation). The turbulent energy budget then is 

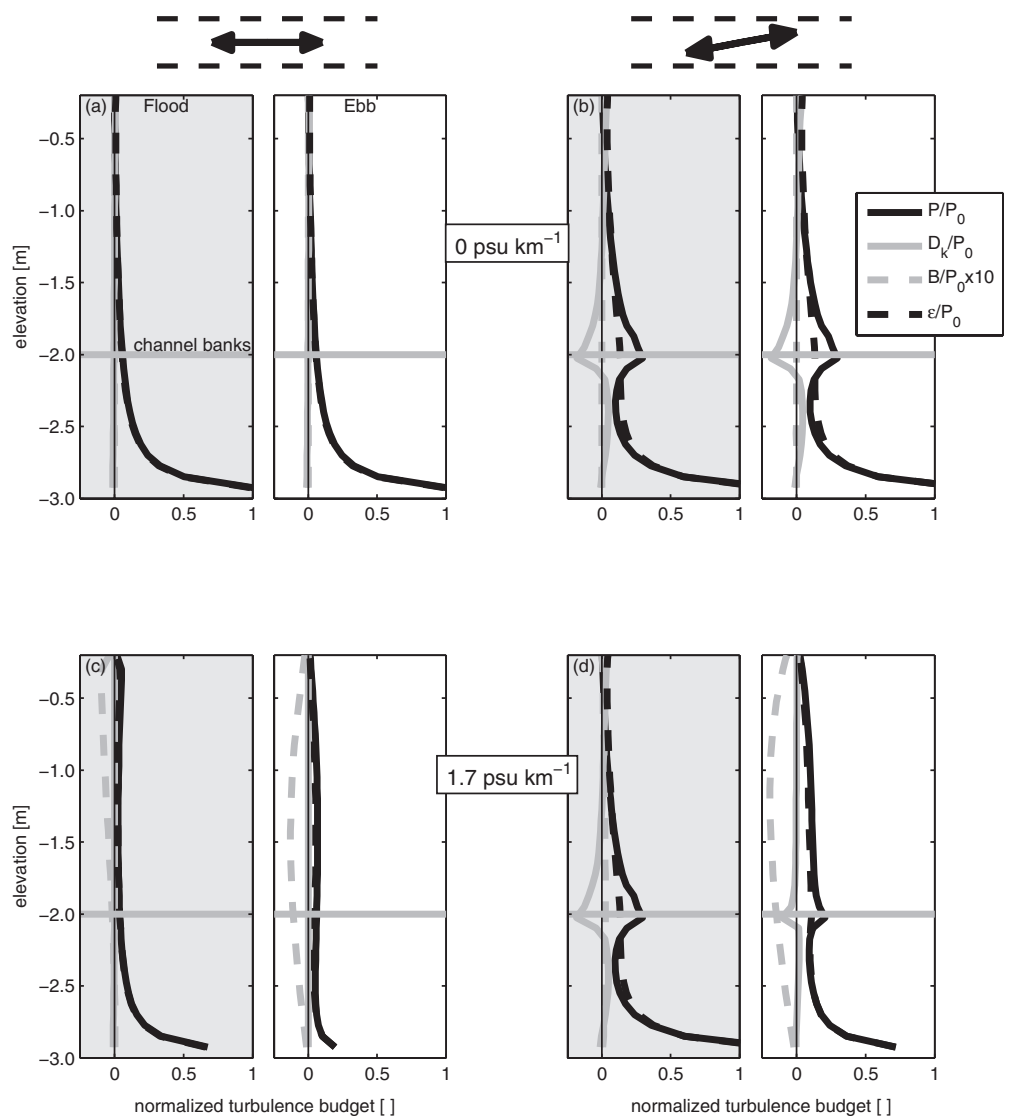

Figure 12. Numerical results of turbulence budgets at peak flood (shaded gray) and ebb for flow along-channel $\left(\theta=0^{\circ}\right.$, left $)$ and across-channel $\left(\theta=10^{\circ}\right.$, right $)$, without and with baroclinic forcing $((\partial S / \partial x=0 \mathrm{psu} / \mathrm{km}$, top; $\partial S / \partial x=1.7 \mathrm{psu} / \mathrm{km}$, bottom). Budget terms are shear production $(P)$, diffusion $\left(D_{k}\right)$, buoyancy production $(B)$, and dissipation $(\varepsilon)$, and are normalized by $P$ at the bed for $\theta=0^{\circ}$ and $\partial \mathrm{S} / \partial \mathrm{x}=0 \mathrm{psu} / \mathrm{km}\left(P_{0}\right)$; buoyancy production is multiplied by 10 for better resolution.

$$
\frac{\partial k}{\partial t}=P+B+D_{k}-\varepsilon
$$

and with the $k-\varepsilon$ closure we quantify each term of the budget to see the fate of turbulence produced by cross-channel shear.

Vertical profiles of the turbulence budget at peak flood and peak ebb velocities are plotted for several cases: flow along the channel axis $\left(\theta=0^{\circ}\right)$ and partially across the channel axis $\left(\theta=10^{\circ}\right)$, both without baroclinic forcing $\left(\partial S / \partial x=0 \mathrm{psu} \mathrm{km}{ }^{-1}\right)$ and with a longitudinal salinity gradient $\left(\partial \mathrm{S} / \partial \mathrm{x}=1.7 \mathrm{psu} \mathrm{km}^{-1}\right)($ Fig. 12). The unsteady term $(\partial k / \partial t)$ is 
always near zero and the balance is predominantly among $P, B, D_{k}$, and $\varepsilon$, so $\partial k / \partial t$ is omitted. The budget terms are all normalized by shear production at the bed for the case of along-channel flow with no salinity gradient $\left(\theta=0^{\circ}\right.$ and $\left.\partial S / \partial x=0 \mathrm{psu} \mathrm{km}^{-1}\right)$; note that normalized buoyancy has been multiplied by a factor of 10 for better resolution on the plots.

During both peak flood and peak ebb for the base case of $\theta=0^{\circ}$ and $\partial S / \partial x=0 \mathrm{psu} \mathrm{km}{ }^{-1}$, the turbulence budget is a balance of shear production and dissipation with each decreasing away from the bed (Fig. 12a). When flow is oriented $10^{\circ}$ off the channel axis there is shear production at the channel banks in addition to that near the bed (Fig. 12b). The shear production locally exceeds dissipation, and therefore diffusion transports turbulent energy to the upper and lower water column where it dissipates. In the near bed and near surface regions, $\varepsilon$ exceeds $P$, so the energy budget balances over the entire water column. With baroclinic forcing, buoyancy production enters the turbulence budget. For along channel flow $\left(\theta=0^{\circ}\right)$ with $\partial S / \partial x=1.7 \mathrm{psu} \mathrm{km}^{-1}$, shear production is damped by buoyancy during both flood and ebb, but much more so during ebbs (Fig. 12c). Tidal straining of $\partial S / \partial x$ increases stratification and suppresses turbulence during ebbs, and remnants of stratification remain through much of the flood so that shear production is lower than in the uniform density case. Buoyancy production is an energy sink throughout the water column at maximum ebb and in the upper water column where stratification remains at maximum flood. When flow is $10^{\circ}$ off the channel axis with $\partial S / \partial x=1.7 \mathrm{psu} \mathrm{km}^{-1}$, buoyancy is no longer an energy sink at peak flood (Fig. 12d). Instead, shear production at the channel banks destroys stratification earlier in the flood, and thereafter tidal straining of $\partial S / \partial x$ makes $B$ a source of turbulent energy. The longitudinal gradient is sufficient that during ebbs straining suppresses shear production both at the channel banks and at the bed. At peak ebb, buoyancy is an energy sink for the production at the channel banks, but for greater flow angle $\theta$ or for lower $\partial S / \partial x$ stratification is also mixed away during ebbs. In those cases the budget closely resembles the case of $\partial S / \partial x=0$, where excess turbulent energy diffuses away from the channel banks.

To consider how conditions evolve with changing flow angle and baroclinic forcing, we break the turbulent energy budget into source terms and sink terms and tidally average water column profiles. The only true source term is shear production $(P>0)$, but in regions away from the channel banks, diffusion can be treated as a source as it transports turbulence from higher energy regions. The energy sink terms are buoyancy production (in stable stratification) and dissipation. The relative contribution of each to the local budget varies with elevation in the water column, with flow angle relative to the channel axis, and with baroclinic forcing (Fig. 13). Diffusion is a local source of energy for the near bed and near surface regions, but near the channel banks diffusion is an energy sink as it transports excess production away and $D_{k}<0$. To quantify the relative contribution of $D_{k}$ as a local source we plot $D_{k} /\left(P+D_{k}(>0)\right)$. Diffusion is more prominent in the budget as the flow 

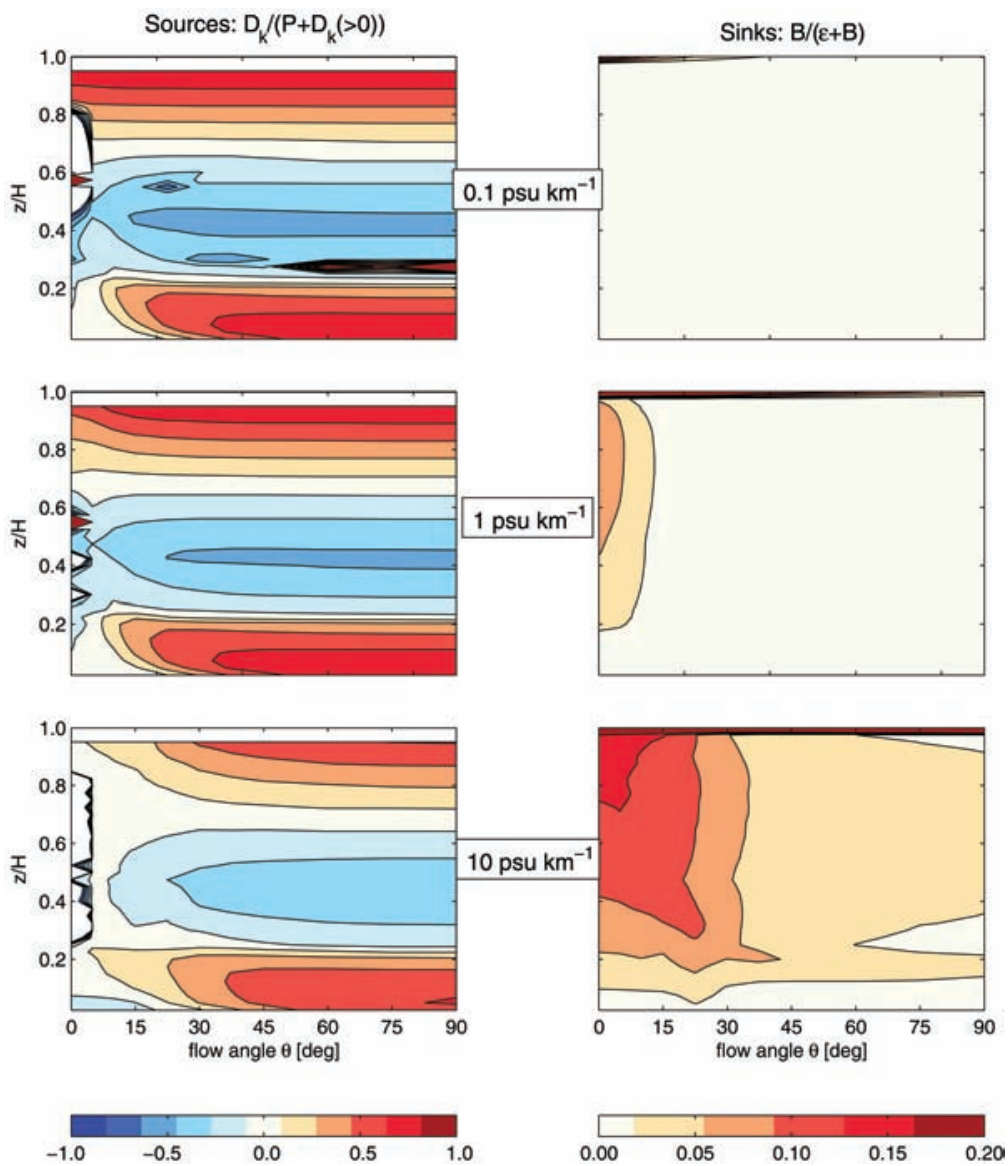

Figure 13. Numerical results of tidally averaged turbulence budget profiles for three different $\partial S / \partial x$ : $0.1 \mathrm{psu} / \mathrm{km}$ (top), $1 \mathrm{psu} / \mathrm{km}$ (middle), and $10 \mathrm{psu} / \mathrm{km}$ (bottom). Local turbulent energy sources (left panels) are shown as the fraction due to diffusion: $D_{k} /\left(P+D_{k}(>0)\right)$; immediately above the channel banks $D_{k}$ is an energy sink so $D_{k} /\left(P+D_{k}(>0)\right)$ is negative. Local turbulent energy sinks (right panels) are given as the fraction due to buoyancy: $B /(\varepsilon+B)$.

angle increases because cross-channel shear production increases and exceeds local dissipation. However, as $\partial S / \partial x$ increases, more of the excess shear production is lost to buoyancy. Buoyancy increases as a sink of turbulent energy as $\partial S / \partial x$ increases, but it also depends on flow angle. As $\theta$ increases, turbulent mixing destroys stratification and eliminates buoyancy production, such that at larger flow angles dissipation is the sole sink of turbulent energy.

A summary of the effects of cross-channel shear can be seen by depth- and tidallyaveraging the components of the turbulence budget (Fig. 14). Total turbulent energy in the water column is largely a function of flow angle, and is relatively independent of baroclinic 

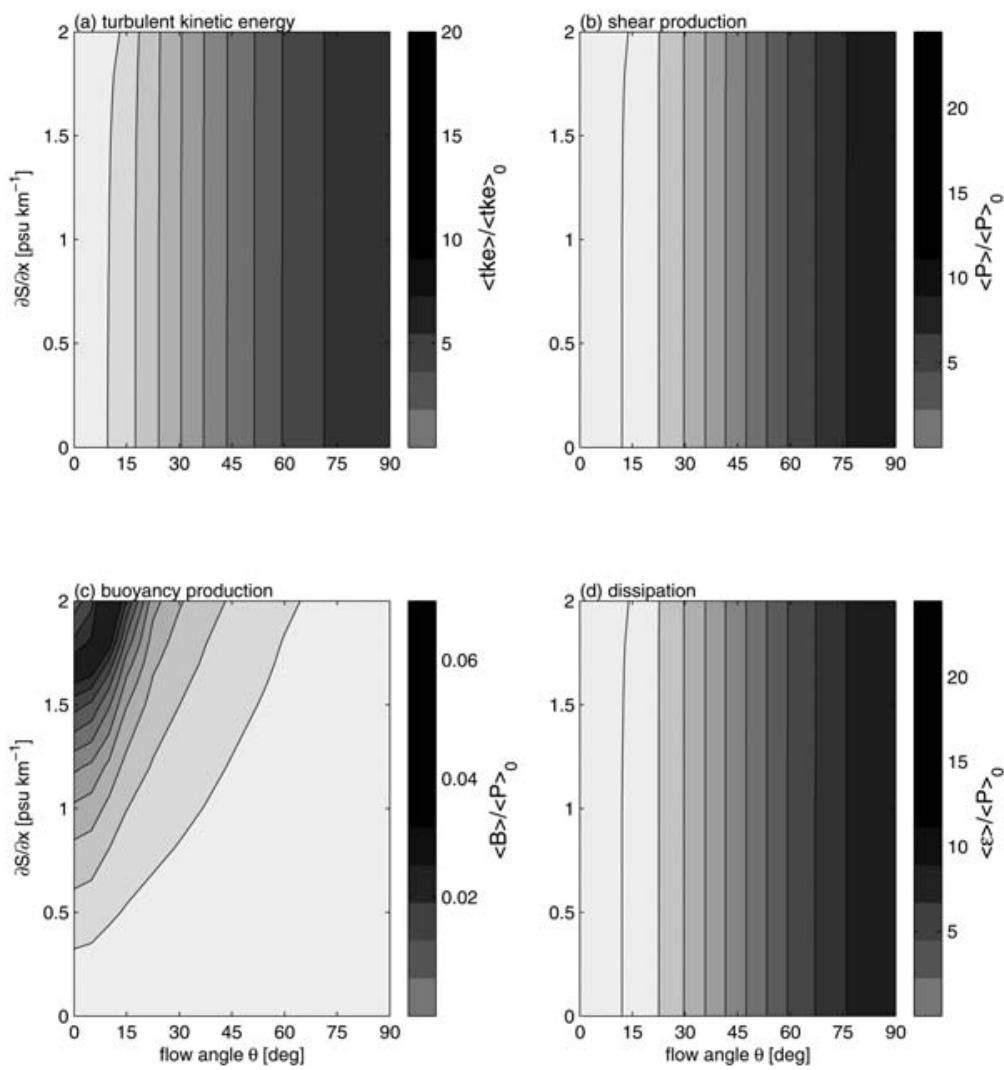

Figure 14. Numerical results of tidally and depth-averaged turbulent energy and turbulence budget components against flow angle $(\theta)$ and $\partial S / \partial x$. (a) Turbulent kinetic energy normalized by $\theta=0$ and $\partial S / \partial x=0 \mathrm{psu} / \mathrm{km}\left(\langle\mathrm{tke}\rangle_{0}\right)$; (b) shear production $(P)$; (c) buoyancy production $(B)$; and (d) dissipation ( $\varepsilon$ ), all normalized by $P$ for $\theta=0$ and $\partial S / \partial x=0 \mathrm{psu} / \mathrm{km}\left(\langle P\rangle_{0}\right)$. Note the scale in (c) is different, and that depth-averaged diffusion is zero.

forcing; with increasing $\theta$, cross-channel shear production increases turbulent energy over the along-channel flow case (Fig. 14a). Shear production with increasing $\theta$ also increases average $\mathrm{P}$ and $\varepsilon$ (Fig. 14b/d). The effect of $\partial S / \partial x$ can be seen at small flow angles as turbulent energy, shear production, and dissipation all decrease with added buoyancy. Depth averaged diffusion is necessarily zero, but buoyancy depends on both the salinity gradient and flow angle (Fig. 14c). Buoyancy is strongest for large $\partial S / \partial x$ and small $\theta$, when tidal straining is uninhibited by cross-channel shear production. However, as $\theta$ increases stratification and buoyancy are destroyed by the additional shear production. The water column turbulence budget above a subtidal channel or other sharp change in bathymetry depends not only on the magnitude, but also the incident angle of the barotropic and baroclinic forcing. 


\section{Summary and discussion}

Based on both field observations and model results, skewed shear over subtidal channels appears to be a significant mechanism for turbulence production. The contribution of cross-channel shear production to the overall turbulence budget depends on bathymetry, tidal forcing, and tidal stage. In all estuarine flows, bathymetry is important because it directs mean flow, removes energy through bed friction and form drag, and generates turbulence at the bed. In many cases bathymetry can be treated as relatively constant over long time scales. However, in the intertidal zone, the interaction between bathymetry and flow dynamics varies over tidal and seasonal time scales. The inundated area changes substantially with stage through the tidal cycle. At lower tidal stages, flow is constrained to narrow channels, while around high water flow is largely over mudflats or vegetated marsh and relatively independent of channel location. Shear across channels depends on both the orientation of the channel with respect to the tidal forcing and the flow depth.

Because of natural sinuosity of mudflat channels, tidal forcing is not always aligned with channel axes. Around high water, flow over the channel banks can generate shear and produce turbulence that significantly increases the turbulent energy mid-water column. Turbulence production depends on the incident angle of the flow relative to the channel. With longitudinal density forcing, turbulence from shear across channels can significantly decrease density stratification. Turbulence production at channel banks can locally exceed dissipation, and the excess energy is consumed by buoyancy or diffuses vertically to the upper or lower water column where it dissipates. The components of the turbulence budget depend on both the flow angle and the longitudinal density gradient.

Cross-channel shear increases turbulent mixing between the channel and the overlying flow. The added mixing is particularly important when water properties in the channel differ from those higher in the water column. Salinity and sediment stratification are possible between the channel bed and adjacent shoals. For example, subtidal channels can store suspended sediment eroded from intertidal mudflats during storms (Yang et al., 2003). Stratification reduces turbulent mixing between channels and overlying flow, further decoupling the regions and increasing shear. When flow is along the channel axis, velocity shear can intensify because of stratification. However, when the barotropic forcing is oblique to the channel, cross-channel shear production can diminish stratification and mix salt or sediment upward in the water column. Mudflat channels are important conduits for scalar fluxes across the intertidal zone (Wells et al., 1990), so the added mixing could impact net scalar transport. Cross-channel shear could also decrease the residual baroclinic transport up channels, similar to increases in turbulent mixing during spring tides in deeper estuaries (e.g., Geyer et al., 2000). For sediment transport, turbulent stress at the channel banks could suspend sediment higher in the water column and allow transport farther across mudflat or marsh surfaces before deposition.

The water column numerical model is a vastly simplified version of the threedimensional flows in the natural environment. By restricting flow in the cross-channel direction in the near-bed cells, we essentially create a narrow channel with vertical walls. 
This is not physically realistic, but it can be a useful approximation for the steep banks of mudflat and marsh channels. Because of the cohesive sediments, subtidal channels can have banks as steep as 30 to 45 degrees (Wells et al., 1990), similar to the channel banks in our field observations. Another limitation of the one-dimensional model is that the barotropic forcing is prescribed rather than adjusting to boundary conditions of a larger system. Shear production due to flow across the channel extracts energy from the bulk flow. Because depth-averaged flow is assigned to find the model solution, the water column dynamics do not feed back to the bulk flow. Despite these limitations, the water column model allows us to create an idealized case that focuses on the vertical structure of turbulence rather than conditions specific to one location. The general case of skewed shear over subtidal channels should be applicable in any system with large variation in flow depth and sinuous channels. Turbulence produced by cross-channel shear can be important for vertical mixing of momentum and scalars, but effects vary with local bathymetry, external forcing, and water depth.

Acknowledgments. The authors thank Matt Brennan, Jon Fram, Maureen Martin, Deanna Sereno, and Stefan Talke for assistance during the field experiments. This research was funded by National Institutes of Health grant no. P42ES0475 from the National Institute of Environmental Health Sciences.

\section{REFERENCES}

Adams, Jr., C. E., J. T. Wells and Y. -A. Park. 1990. Internal hydraulics of a sediment-stratified channel flow. Mar. Geol., 95, 131-145.

Baines, P.G. 1995. Topographic Effects in Stratified Flows. Cambridge University Press, 482 pp.

Bridges, P. H. and M. R. Leeder. 1976. Sedimentary model for intertidal mudflat channels, with examples from the Solway Firth, Scotland. Sedimentology, 23, 533-552.

Boyer, D. L. and P. A. Davies. 2000. Laboratory studies of orographic effects in rotating and stratified flows. Ann. Rev. Fluid Mech., 32, 165-202.

Burchard, H. 1999. Recalculation of surface slopes as forcing for numerical water column models of tidal flow. Appl. Math. Model., 23, 737-755.

Burchard, H. and H. Bolding. 2001. Comparative analysis of four second-moment turbulence closure models for the oceanic mixed layer. J. Phys. Oceanogr., 31, 1943-1968.

Burchard, H., K. Bolding and M. Ruiz Villarreal. 1999. GOTM-a general ocean turbulence model, theory, applications and test cases, Tech. Rep. EUR 18745 EN, European Commission.

Canuto, V. M., A. Howard, Y. Cheng and M. S. Dubovikov. 2001. Ocean turbulence. Part I: One-point closure model - momentum and heat vertical diffusivities. J. Phys. Oceanogr., 31, 1413-1426.

Chant, R. J. and A. W. Stoner. 2001. Particle trapping in a stratified flood-dominated estuary. J. Mar. Res., 59, 29-51.

Fagherazzi, S. and D. J. Furbish. 2001. On the shape and widening of salt marsh creeks. J. Geophys. Res., 106, 991-1003.

Fagherazzi, S., E. J. Gabet and D. J. Furbish. 2004. The effect of bidirectional flow on tidal channel planforms. Earth Surf. Process. Landforms, 29, 295-309.

Fernando, H. J. S., S. M. Lee, J. Anderson, M. Princevac, E. Pardyjak and S. Grossman-Clarke. 2001. Urban fluid mechanics: air circulation and contaminant dispersion in cities. Env. Fluid Mech., 1 , 107-164. 
Friedrichs, C. T. 1995. Stability shear stress and equilibrium cross-sectional geometry of sheltered tidal channels. J. Coast. Res., 11, 1062-1074.

Friedrichs, C. T. and J. E. Perry. 2001. Tidal salt marsh morphodynamics: a synthesis, J. Coastal Res., SI 27, 7-37.

Gabet, E. J. 1998. Lateral migration and bank erosion in a saltmarsh tidal channel in San Francisco Bay, California. Estuaries, 21, 745-753.

Geyer, W. R., J. H. Trowbridge and M. M. Bowen. 2000. The dynamics of a partially mixed estuary. J. Phys. Oceanogr., 30, 2035-2048.

Lawrence, D. S. L., J. R. L. Allen and G. M. Havelock. 2004. Salt marsh morphodynamics: an investigation of tidal flows and marsh channel equilibrium. J. Coast. Res., 20, 301-316.

Li, C., A. Valle-Levinson, K. C. Wong and K. M. M. Lwiza. 1998. Separating baroclinic flow from tidally induced flow in estuaries. J. Geophys. Res., 103, 10405-10417.

Monti, P., H. J. S. Fernando, M. Princevac, W. C. Chan, T. A. Kowalewski and E. R. Pardyjak. 2002. Observations of flow and turbulence in the nocturnal boundary layer over a slope. J. Atmos. Sci., 59, 2513-2534.

Peters, H. 1999. Spatial and temporal variability of turbulent mixing in an estuary. J. Mar.Res., 57, 805-845.

Ralston, D. K. and M. T. Stacey. 2005a. Longitudinal mixing and lateral circulation in the intertidal zone. J. Geophys. Res., 110, C07015, doi:10.1029/2005JC002888.

- 2005b. Stratification and turbulence in subtidal channels through intertidal mudflats. J. Geophys. Res., 110, C08009, doi:10.1029/2004JC002650.

Rodi, W. 1987. Examples of calculation methods for flow and mixing in stratified fluids, J. Geophys. Res., 92, 5305-5328.

Simpson, J. H., J. Brown, J. Matthews and G. Allen. 1990. Tidal straining, density currents, and stirring in the control of estuarine stratification. Estuaries, 13, 125-132.

Simpson, J. H., H. Burchard, N. R. Fisher and T. R. Rippeth. 2002. The semi-diurnal cycle of dissipation in a ROFI: model-measurement comparisons. Cont. Shelf Res., 22, 1615-1628.

Umlauf, L. and H. Burchard. 2003. A generic length-scale equation for geophysical turbulence models. J. Mar. Res., 61, 235-265.

Uncles, R. J. 2002. Estuarine physical processes research: some recent studies and progress. Estuar. Coast. Shelf Sci., 55, 829-856, doi:10.1006/ecss.2002.1032.

Valle-Levinson, A. and L. P. Atkinson. 1999. Spatial gradients in the flow over an estuarine channel. Estuaries, 22, 179-193.

Valle-Levinson, A., C. Li, K. -C. Wong and K. M. M. Lwiza. 2000. Convergence of lateral flow along a coastal plain estuary. J. Geophys. Res., 105, 17045-17061.

van Gorsel, E., A. Christen, C. Feigenwinter, E. Parlow and R. Vogt. 2003. Daytime turbulence statistics above a steep forested slope. Boundary-Layer Meteor.., 109, 311-329.

Wells, J. T., C. E. Adams, Y. A. Park and E. W. Frankenberger. 1990. Morphology, sedimentology and tidal channel processes on a high-tide-range mudflat, west coast of South Korea. Mar. Geol., 95, 111-130.

Wells, J. T. and Y. A. Park. 1992. Observations on shelf and subtidal channel flow: implications of sediment dispersal seaward of the Keum River Estuary, Korea. Estuar. Coast. Shelf Sci., 34, 365-379.

Wolanski, E., J. Chappell, P. Ridd and R. Vertessy. 1988. Fluidization of mud in estuaries. J. Geophys. Res., 93, 2351-2361.

Wong, K .-C. 1994. On the nature of transverse variability in a coastal plain estuary. J. Geophys. Res., 99, 14209-14222. 
Wong, K. -C. and J. E. Moses-Hall. 1998. The tidal and subtidal variations in the transverse salinity and current distributions across a coastal plain estuary. J. Mar. Res., 56, 489-517.

Yang, S. -L., C. T. Friedrichs, Z. Shi, P. -X. Ding, J. Zhu and Q. -Y. Zhao. 2003. Morphological response of tidal marshes, flats, and channels of the Outer Yangtze River mouth to a major storm. Estuaries, 26, 1416-1425.

Received: 22 June, 2005; revised: 20 October, 2005. 